\title{
Using Tablet Applications for Children With Autism to Increase Their Cognitive and Social Skills
}

Journal of Special Education Technology I-II

(C) The Author(s) 2017

Reprints and permission:

sagepub.com/journalsPermissions.nav DOI: $10.1|77 / 01626434177| 975 \mid$

journals.sagepub.com/home/jst

(S)SAGE

\author{
Marco Esposito', Janette Sloan ${ }^{2}$, Andrea Tancredi ${ }^{3}$, Giovanna Gerardi ${ }^{\text {, }}$ \\ Paola Postiglione' ${ }^{\prime}$ Francesca Fotia', Eleonora Napoli ${ }^{4}$, Luigi Mazzone ${ }^{4}$, \\ Giovanni Valeri ${ }^{4}$, and Stefano Vicari ${ }^{4}$
}

\begin{abstract}
Several researchers along with technicians have been developing software and hardware to support and/or replace the standard method of teaching for children with autism spectrum disorders (ASDs) and/or other developmental disabilities. Moreover, computer-based intervention and electronic tablets have shown benefits for people with special needs increasing their independence, academic and cognitive skills, social communication, and leisure time. Therefore, the aim of the current study is to evaluate the effectiveness of three tablet applications created to enhance specific abilities of children with ASD (attention, vocabulary, and imitation), who followed applied behavior analysis treatment (ABA) compared with the internal control group (CG). Training lasted 4 weeks for 15 children selected in a randomized way, while the CG followed only the behavioral therapy. To sum up, we want to respond to three questions: (I) whether the experimental group (EG) using the applications obtains greater progress within standard therapy in comparison to the CG, (2) whether the real skills of children examined at baseline have an impact on the application scores, and (3) whether the graphic features of the applications influence the motivation of children during training. At postintervention assessment, the EG showed higher progress within standard therapy than the internal CG even though these differences didn't overreach the significance level. However, the probability of making progress in mastered targets at postintervention assessment was higher for the EG than the CG. To conclude, the current study demonstrates the capability of tablet applications to reproduce effective educational training for children with autism.
\end{abstract}

\section{Keywords}

autism, exceptionality, applied behavior analysis, methodologies, APPS, technology perspectives, tablets/iPad, group design

People with autism spectrum disorders (ASDs) are characterized by social communication deficit and a tendency to engage in a pattern of restricted and repetitive behavior (American Psychiatric Association, 2013). Moreover, children with ASDs can present impairments in a large variety of developmental abilities, from social-cognitive to fine motor skills. Although cases of autism have been increasing, currently effective educational interventions for these children are widely diffused, and progress has been demonstrated in intellectual, language, and adaptive skills (Warren et al., 2011). At the same time, several researchers, along with technicians, have been developing software and hardware to support and/or replace the standard method of teaching, including computer-based intervention, electronic tablets, robots, and virtual reality in order to boost the learning skills of people with autism. Essentially, traditional technology (desktop computers, laptops, videotape, etc.) and handheld electronic devices (smartphones, electronic tablets, and personal digital assistance) created for children, adolescents, and adults with ASDs and/or intellectual disabilities (ID) have already shown benefits, increasing their independence, academic, and cognitive skills, and improving social communication and leisure time (Grynszpan, Weiss, PerezDiaz, \& Gal, 2014; Kagohara et al., 2013; Odom et al., 2015; Stephenson \& Limbrick, 2015; Wass \& PorayskaPomsta, 2014).

\footnotetext{
'Autism Research and Treatment Centre "Una Breccia nel muro", Rome, Italy

${ }^{2}$ The Cambridge School, Salerno, Italy

${ }^{3}$ Memotef Department, University of Rome "La Sapienza”, Rome, Italy

${ }^{4}$ Neuroscience Department, Pediatric Hospital Bambino Gesù, Rome, Italy

Corresponding Author:

Marco Esposito, Autism Research and Treatment Centre "Una Breccia nel muro", Rome 00168, Italy.

Email: marco.esposito@unabreccianelmuro.org
} 


\section{Using Touch Devices as Educational Tools}

In particular, touch devices (such as the iPod Touch, iPads, smartphones, and others) have intrinsic advantages (they are user-friendly, readily available, relatively inexpensive, and portable), and above all among youngsters are the preferred learning channel and therefore have been applied by trainers (researchers, psychologists, and therapists) in different settings (hospital, school, home, and community). To date, search engines allow us to find different typologies of tablet and smartphone applications for people with ASD, choosing them by category, price, and specific programs. Some of these applications seek to recover cognitive and social ability and daily living skills, by visual support, video modeling, and token economy programs (Lofland, 2016), even though the efficacy of most of these has not been validated by research designs.

\section{Academic Skills}

Some researchers have shown that an iPad Touch1 was used by two children (Asperger's syndrome and attention deficit hyperactivity disorder diagnosis) to check the spelling of words on a computer word processor, including video modeling and reinforcement schedules (Kagohara, Sigafoos, Achmadi, O’Reilly, \& Lancioni, 2012). Similarly, Kinney, Vedora, and Stromer (2003) taught one child with ASD to spell with video modeling, using a PowerPoint presentation (Dell Inspiron 3800 authored in Microsoft PowerPoint). Moreover, we report one study regarding learning written language, using video selfmodeling for three adolescents with Asperger's syndrome (Delano, 2007). Finally, some researchers have taught numeracy skills to one child with ASD, with the support of an iPad with video modeling (Jowett, Moore, \& Anderson, 2012).

\section{Vocabulary}

To increase the vocabulary of children with ASDs, other scientists used TeachTown, a training system based on applied behavior analysis (ABA) procedures for preschool children (Whalen et al., 2010). TeachTown consists of computer lessons offering an individualized learning environment where the child works on the computer and completes lessons that incorporate $\mathrm{ABA}$ techniques (prompting, errorless teaching, fading or increasing of distractors, verbal praise, and other reinforcements). The training package uses discrete trial teaching (DTT), where verbal instructions are given by the game and the child clicks on the correct item from a field of three to eight choices. Thus, a large variety of images are utilized to facilitate generalization. Difficulty is gradually implemented, respecting the child's game progress. At the end of training, the child can access an animated reward game lasting 15-45 s. A similar program will be proposed in the current research using tablet applications. Lastly, another computer program was implemented to increase vocabulary skills for children with autism. The computer package created combined attention-getting features, such as sound effects, colors, animation, and music, with behavioral methods, such as chaining and immediate contingent reinforcements (Moore \& Calvert, 2000). The children using the computer program, who were included in the experimental condition, showed better results than with traditional teaching regarding the acquisition of nouns, attention, and motivation.

\section{Communication Skills}

Regarding assistive communication apps, some researchers demonstrated the effectiveness of Proloquo2GoTM and Pick a Word software to make requests for preferred stimuli by selecting icons from an iPod Touch or iPad through prompting procedures, physical guidance, backward chaining, and differential reinforcements for children and adolescents with ASD at school (Achmadi et al., 2012; Flores et al., 2012; Kagohara et al., 2010; van der Meer et al., 2011). Also, using the same software, children displayed better maintenance of requests than manual signs communication system (van der Meer, Didden, et al., 2012; van der Meer, Kagohara, et al., 2012; van der Meer, Sutherland, O'Reilly, Lancioni, \& Sigafoos, 2012).

\section{Daily Living Skills}

Moreover, scientists have applied technologies (iPod and iPhone) by video training with Clock/Storykit/VoCal/iCal/ iTunes and other applications to train people with autism to improve their daily living skills (reaching places, cleaning the bathroom, emptying garbage, sweeping the dining area, fire safety training, etc.) and employment (cleaning offices, sorting e-mails, and caretaker duties; Burke, Andersen, Bowen, Howard, \& Allen, 2010; Cihak, Fahrenkrog, Ayres, \& Smith, 2010; Gentry, Lau, Molinelli, Fallen, \& Kriner, 2012).

\section{Social Skills}

The priority areas of intervention in ASDs are to improve the quality of social interaction for children and youths with these deficits (eye contact, joint attention, turn taking, play skills, expressing emotion, theory of mind, pragmatic of language, etc.) and to create specific games and applications to improve these abilities through a supportive eye contact application (Jeffries, Crosland, \& Miltenberger, 2016), cooperative games on tabletop (Piper, O'Brien, Morris, \& Winograd, 2006), collaboration in the context of storytelling on Diamond Multitouch for children with ASD (Gal et al., 2009), and to cooperate using musical and problem-solving tablet applications (Hourcade, Bullock-Rest, \& Hansen, 2012). In the first study, the authors tried to increase the frequency of eye contact of three children with autism during Mand training with a therapist, through a tablet application that demanded a matchto-sample response of a number situated on the eyes to a grid. The children responded to questions such as "What number did you see?" After four tokens received for correct responses, they could access an interactive game as reinforcement. However, in this case, the training was not effective in improving eye contact in contrast to a face-to-face differential reinforcement technique. 


\section{Creating Successful Games for Children With Autism}

In order to create successful games for children with neuropsychiatric disorders, in recent years, an approach called "serious game design" has focused on the integration of educational goals with evidence-based game mechanics, acknowledged to support learning, and generalization of skills acquired (Whyte, Smyth, \& Scherf, 2015). To date, diverse elements have been found to be effective in fostering motivation and learning during the game. The first is the creation of a story line or narrative that explains the future goals of the game. Above all, the story lines, which introduce specific characters, can encourage the social skills of children by their identification. Another essential characteristic is the help provided by a mentor, who gives step-by-step guidance to the children (Marchiori et al., 2012). The levels of the game should also offer a gradual increment of difficulty, with some clear intermediate or final goals. Token economy strategies are habitually implemented for earning collectable rewards to reach the final objective in the game, while increasing the motivation of players. On the other hand, serious games can provide feedback related to goals achieved, enhancing motivation for learning and showing visual progress. Lastly, the provision of choice to players is another important feature to promote their intrinsic motivation and enjoyment (Ryan, Rigby, \& Przybylski, 2006). Thus, as described in the review, children and adolescents with autism can be sensitive to some graphic and structural aspects of the game realized on a tablet or computer. For example, they seem to prefer short games with continuous acoustic and visual feedback, self-managing and free choice of the tasks, familiar activities, and the least possible burden on fine motor movements. All of these features can guarantee better results to professionals who put effort into creating successful applications for children with ASD.

However, although the number of interesting tablet applications for children has been increasing, there are still very few randomized control studies on their effectiveness, with poor samples and a lack of comparison between different groups, in spite of the fact that the literature on this topic appears to have demonstrated advantages for people with ASD. Furthermore, these studies report minimal or poor generalization of learning, with no or poor transfer to real social interactions as suggested by the serious game design approach.

Therefore, the aim of this study is to evaluate the effectiveness of three tablet applications created to enhance specific abilities of children with ASD (attention, vocabulary, and imitation) who followed ABA treatment, compared with the control group (CG; children who followed only $\mathrm{ABA}$ intervention). To sum up, we endeavor to respond to three relevant questions: (1) whether the experimental group (EG) following training with tablet applications obtains greater progress within standard therapy in comparison to the $\mathrm{CG}$ (the dependent variable will be represented by the acquisition of the behavioral targets of standard therapy), (2) whether the real skills of children examined at baseline of standard therapy, for example, to imitate the therapist and respond to their instructions, have an impact on the application scores, and (3) whether the graphic features and structure of the three electronic applications influence the motivation and relative scores of children during the game time.

\section{Method}

Participants $(N=30)$ aged 47 months average $(S D=14.37$; 27 males) were selected on the basis of the diagnosis of ASD, made by experienced clinicians operating in the "Pediatric Hospital Bambino Gesù" in Rome, based on the criteria of the Diagnostic and Statistical Manual of Mental Disorders (DSM-IV-TR) and assessments by means of standardized diagnostic instruments, that is, the Autism Diagnostic Observation Schedule-Generic (ADOS-G; Lord, Risi, Lambrecht, Cook, \& Leventhal, 2000), the Autism Diagnostic Interview-Revised (ADI-R; Lord, Rutter, \& Le Couteur, 1994), the Griffiths Mental Developmental Scale-Extend Revised (GMDS-ER; Griffiths, 2006), and the Vineland Adaptive Behavior Scales (VABS; Sparrow, Balla, \& Cicchetti, 1984). Note that we conducted the study prior to the variation in diagnostic criteria for ASD. Children were not recruited if they had seizures, were 6 years of age or older, and had additional medical diagnoses (e.g., genetic syndromes). All the children were Italian and for 1 year followed comprehensive ABA treatment that included $6 \mathrm{hr}$ a week of 1:1 therapy with a behavioral therapist (half of the time was spent in quasi-natural settings) divided between DTT and naturalistic environment teaching (Sundberg \& Partington, 1999) at the research and treatment center "Una Breccia nel muro," through a modification of a previous clinical model (Fava \& Strauss, 2011).

The clinical staff was independent from research staff and blinds to the hypotheses of the intervention study. The therapists and supervisors had at least a master's degree in applied behavior analysis and 2 years of experience in treatment of children with ASD. Each child's skills, strengths, and deficits were also evaluated on the basis of their performance in the Assessment of Basic Language and Learning Skills (ABLLS; Partington \& Sundberg, 1998) carried out by the assigned supervisor. The ABLLS was used both to identify learning goals and to control either progress or regression during the standard treatment. Additionally, the intervention comprised direct supervision ( $1 \mathrm{hr}$ a week) by an expert professional to ensure the reliability of teaching procedures and parent inclusion (parents spent $2 \mathrm{hr}$ a week in the therapy room with clinical staff). Parents followed a parent training course at the beginning of the behavioral program with an expert supervisor on six main units (evidence-based treatments, teaching methodologies, verbal behavior approach, augmentative alternative communication, analysis and management of challenging behaviors, and development of play skills). Each unit lasted $3 \mathrm{hr}$ and after the course parents took part in the treatment by first observing and then implementing the ABA therapy with their children. Parents were asked to follow their children for $1 \mathrm{hr}$ a day on the generalization and maintenance 
Table I. Differences on All Variables at Baseline Assessment Between Experimental and Control Group.

\begin{tabular}{|c|c|c|c|c|c|c|c|}
\hline Characteristic & Variables & $\begin{array}{l}\text { Experimental } \\
\text { Group }(n=15) \\
\text { Mean }(S D) / \\
\text { Proportion }\end{array}$ & Range & $\begin{array}{c}\text { Control } \\
\text { Group }(n=15) \\
\text { Mean }(S D) / \\
\text { Proportion }\end{array}$ & Range & $\begin{array}{c}\text { Group } \\
\text { Difference } \\
t(d f) / z\end{array}$ & $\begin{array}{c}p \\
\text { Value }\end{array}$ \\
\hline Gender & Male & 0.87 & & 0.93 & & -0.608 & .543 \\
\hline Age & Months & $45.5(14.1)$ & $25-68$ & $48.5(15)$ & $26-70$ & $-0.555(28)$ & .585 \\
\hline Intensity of standard therapy & Hours a week & $6(0)$ & & $6(0)$ & & & \\
\hline \multirow{2}{*}{ ADOS-G } & Social interaction & $10.5(1.9)$ & $7-12$ & II.I (3.I) & $5-15$ & $-0.506(15)$ & .62 \\
\hline & Total score & $16.1(3.2)$ & $12-20$ & $15.1(4.1)$ & $8-22$ & $0.599(17)$ & .557 \\
\hline \multirow[t]{4}{*}{ VABS } & Communication & $2.2(1.7)$ & $1.6-6.6$ & $1.6(0.1)$ & $1.6-1.9$ & $1.068(8)$ & .316 \\
\hline & Daily living skills & $2(0.8)$ & $1.1-3.8$ & $2(0.5)$ & $1.6-3.0$ & $0.22(13)$ & .983 \\
\hline & Socialization & $1.7(0.5)$ & $1.1-2.8$ & $1.7(0.3)$ & I.I-2.I & $0.449(14)$ & .66 \\
\hline & Motor skills & $2.2(0.7)$ & $1.1-3.8$ & $2(0.6)$ & $1.1-3$ & $0.374(14)$ & .714 \\
\hline $\begin{array}{l}\text { Mastered targets standard } \\
\text { therapy }\end{array}$ & $\begin{array}{l}\text { Receptive identification of } \\
\text { objects }\end{array}$ & $41.9(45.5)$ & $2-60$ & $42.3(60.4)$ & $0-212$ & $-0.024(26)$ & .981 \\
\hline
\end{tabular}

Note. ADOS-G = Autism Diagnostic Observation Schedule-Generic (Lord et al., 2000) with the following scales communication (cutoff for autism = 4, cutoff for spectrum $=2$ ), social interaction (cutoff for autism $=7$, cutoff for spectrum $=4$ ), and total score (cutoff for autism $=1 \mathrm{I}$, cutoff for spectrum $=6$ ); VABS $=$ Vineland Adaptive Behavior Scales (Sparrow et al., 1984), the VABSs show the associated age equivalent scores; GMDS-ER = Griffiths Mental Developmental Scale-Extend Revised (Griffiths, 2006), we report standard scores on the general developmental quotient (GQ; $M=100, S D=I 5)$ and the related levels of mental retardation (profound: <32; severe: 32-44; moderate: 45-57; and mild: 57-74; Ivens \& Martin, 2002).

of the targets acquired with the therapist at the center, generally in the afternoons at home, when therapy with staff had been concluded. The parents presented the natural activities on mand training, generalization of cognitive targets, management of challenging behaviors, development of autonomies, and functional play activities. Data from the standard therapy were gathered from data sheets provided by supervisors for both therapists and parents. During the training with tablet applications, none of these aspects were changed in order to guarantee the greater reliability of the internal validity of the study.

The individualized educational plan for the children involved preschool goals regarding communication, attention, imitation, social play, gross and fine motor skills, receptive and expressive language, and autonomy. Subsequently, the sample was divided into two parts, with randomized assigning of the children to two test conditions (training and internal control), so 15 children were assigned to an EG and the others constituted an internal CG. The groups were not significantly different on all variables at baseline assessment (see Table 1). No other behavioral interventions were undertaken during the experiment for any of the children.

The research was conducted with the prior consent of both parents and with the approval of the host institution. The project was submitted for prior approval to the local ethics committee and conducted in compliance with the Code of Ethics of Research in Psychology in accordance with national (Code of Ethics Italian Association of Psychologists [AIP]) and international guidelines (Code of Ethics Society for Research in Child Development).

\section{Training With Tablet Applications}

For this study, we added daily practice $(30 \mathrm{~min})$ with three tablet applications (attention, vocabulary, and imitation) to the EG to verify an increment in the children's mastered targets after 4 weeks, while the CG followed only the standard therapy described above. In reality, before the beginning of the experiment, the research staff developed a single test for a month with one child to guarantee the reliability of the electronic products. The single child who used the applications was excluded from the experiment with the groups, respecting the gradual research phases (Smith et al., 2007). Successively, the games were practiced at the children's homes with the assistance of parents, generally in the afternoons when the educational therapy had been concluded. Prior to the experiment, the parents of participants were trained in the use of the applications ( $1 \mathrm{hr}$ of consultation with the research coordinator and one with a technician) in order to support the child throughout the practice and to offer informatics assistance. Note that parents already knew much of the effective teaching methodologies, having theoretical and practical knowledge of behavioral treatments, so the researchers explained only how to train their child to access and to manage the applications. For any problems, the parents could contact the project staff throughout the training. Access to the games was protected by a user name and personal password issued by a member of the project staff. The progress by game scores was monitored daily through an online database via Wi-Fi connection. After 4 weeks, we asked parents to stop the access to games and the applications were returned to the 
research staff. In order to respond to the three hypotheses of the study, real (standard therapy) and virtual progress (game scores) of children pre- and postintervention was gathered to compare groups.

\section{Characteristics and Contents of Applications}

Researchers at the center, along with external technicians (engineers, programmers, designers, and computer scientists) and a project manager, set up a project called Brecciapps, designed to create games for children with autism with the aim to transfer educational activities from the practical experience of clinical staff to tablet applications. At the end of the project, the research staff produced 80 applications to support the same areas of the ABA treatment. The games included behavioral strategies such as discrete trials, gradual advance of difficulty, alarms, rewards and feedback on performance, prompting and fading techniques, and multiple choice for various games to foster motivation and enjoyment (Ryan et al., 2006). In addition, an animated tutor showed the tasks required of the player beforehand in order to reduce errors (Marchiori et al., 2012). The goal was to provide not-too-easy and not-too-difficult targets to maintain higher motivation, integrating learning theory with technology tools (Whyte et al., 2015). Essentially, the content of three apps was represented by simple-to-complex time-based barrage tasks (attention app), as the player had to tap various stimuli such as fish and farm animals, avoiding distractors; this game also provided multiple choices about what scenery the child preferred. The second app regarded the discrimination of words heard in discrete trials (vocabulary app): For example, the items were represented by animals, vehicles, musical instruments, and household objects. The players had to choose the correct item from a field of at least three images after the narrator asked a question such as "where is the cow?" Finally, the third app was characterized by the imitation of actions with objects (imitation app) such as rocking a doll, moving a toy car, and so on, respecting the visual model (see Figure 1). After three correct responses per task, the children received an animated reinforcement lasting $30 \mathrm{~s}$, while the multiple choice in the discrete trial format was always given in a field of a minimum of three choices. To increase motivation during the game, vocal and written praise was delivered after every correct response along with a funny animation of the objects (e.g., the fish became colored and bigger). Likewise, if the children failed to respond in time or made mistakes, the applications delivered a prompt (e.g., the object became larger or brighter). The instructions delivered by the applications were the same as the standard therapies provided by therapists. For example, during DTT sessions of the ABA therapies, professionals had a list of behavioral targets (flashcards or objects) and through verbal instruction, such as "do this" for imitation/attention targets and "where is the cat?" for vocabulary, taught children skills with prompting, fading, and reinforcement techniques. Thus, programmers transferred target lists and related instructions within the three applications. This parallelism between therapy sessions and applications

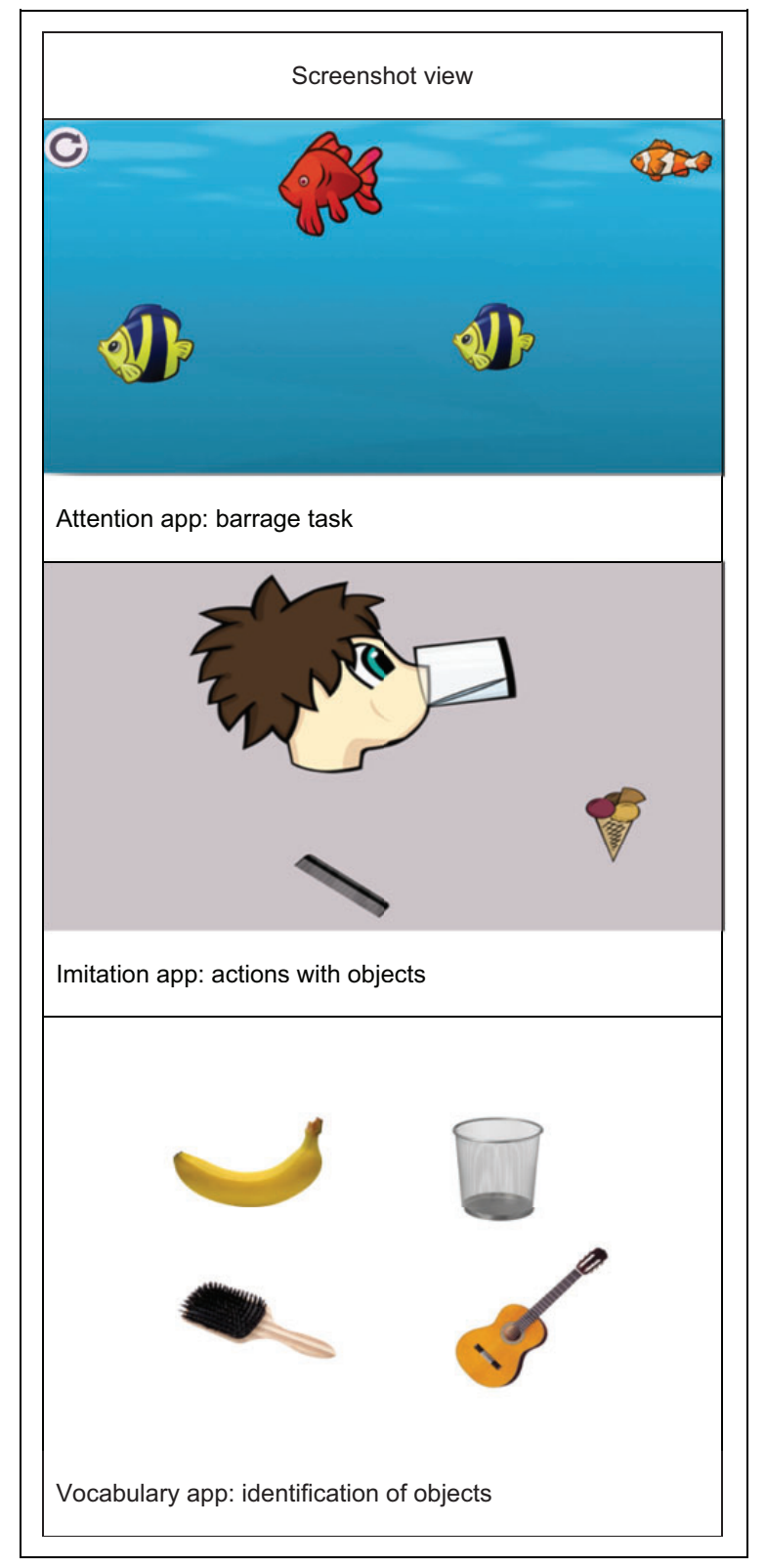

Figure I. Examples of the games.

would not have lead to greater reliability of virtual teaching, considering that the technology would never have been able to comprise all aspects of social interactions.

All games were performed on an ASUS-K010 tablet with android system. The web platform to pick games data was produced on cloud and was developed using the following technologies: MongoDB (database), ExpressJS (web server), AngularJS, and NodeJS (programming language for client and server). The games were created through two different technologies, Game Closure and Construct 2: the first was used for the applications that needed granular control. In addition, the applications contained a module/library of analytics, permitting parents to $\log$ in and save the children's performances. In this way, the researchers could observe the children's daily progress by game scores. 
Journal of Special Education Technology $X X(X)$

\section{Assessment of Game Scores}

We have collected the following measures regarding the three applications only for children who participated in the experiment: every access to applications, the number of correct responses (the incorrect responses were about latency and topography), the best scores with the related best sessions, the means of the scores across all sessions, and finally, the time spent on apps, to control the reliability of training. The game scores regarding the three apps at baseline were represented by the average of the first three sessions in order to avoid an underestimation of the children's performances. In addition, we detected every crash and malfunction of the system, such as the problems reported by parents. The common gaps were represented by unexpected freezing of games or the lack of Wi-Fi connection.

\section{Assessment of Standard Therapy}

Each therapy session consisted of nine teaching trials for each acquisition, mixed with trials that assessed previously mastered targets. The therapists taught more than one acquisition target during an instructional session in accordance with the daily educational plan made by an assigned supervisor (generally not more than eight acquisition targets a day). If there was not enough time left to complete the daily program during a session, the therapists taught from three to five acquisition targets only. The therapist presented the initial instruction at the start of each trial and waited $3 \mathrm{~s}$ for the child's response. If the child responded incorrectly or did not respond, the therapist delivered a prompt. The therapist faded the prompts by progressing from the most intrusive to the least intrusive prompts across trials. Likewise, the therapists offered differential reinforcement in order to increase the frequency of behavior. Teaching terminated following a minimum of three consecutive sessions with (a) correct unprompted responses at or above $88 \%$ of the trials (continuous data) and (b) a correct unprompted response on the first trial (Lerman, Dittlinger, Fentress, \& Lanagan, 2011). One session a week was assessed for the therapist's adherence to the teaching procedures $(n=4$ sessions in a month). Interobserver agreement ranged from $79 \%$ to $100 \%$. Subsequently, the sum of the mastered targets was collected only for three educational programs connected to the exercises of the applications, such as attention, receptive identification of objects, and the imitation of actions with objects. The attention program grouped the following targets: immediate response to name, or during play and conversation, maintaining eye contact for $5 \mathrm{~s}$, joint attention, and selective attention by barrage tasks. The receptive identification of objects program included the discrimination of words heard regarding common objects (animals, body parts, foods, musical instruments, cartoons, etc.) and lastly, the imitation of actions with objects program asked children to replicate the action of the therapist (rocking a doll, waving a flag, moving a car, beating a drum, drinking from a glass, etc.). To clarify, pre- and postexperiment, the means of the mastered targets for these three educational programs were chosen as criteria to compare both groups, evaluating the effects of the tablet applications training.

\section{Results \\ Analytical Approach}

Firstly, a set of descriptive analyses on the sample was conducted either on the characteristics of participants or on tablet applications data. To verify whether groups differed at baseline and postintervention, we applied $t$-test analysis between the groups, as the data met the assumption of normal distribution. As a dependent variable, we selected the means of the mastered targets of standard therapy. Subsequent logistic regression analysis, considering the improvement in the target score after the experiment, was applied to investigate whether it could represent an advantage in learning within standard therapy for the children taking part in the EG. A correlational analysis using Pearson's coefficient was then conducted to study the relationship between time spent on games and outcomes. This analysis was applied to control the effect of the intensity of the exercise. The correlation analysis was conducted by selecting a significance level $\alpha<.05$. Finally, linear regressions were conducted to control the value of possible predictors. We were interested in exploring the association between the real abilities of children at baseline on game scores and if the applications could be capable of eliciting the same behaviors requested in the face-to-face therapy. Data analysis was performed using the $R$ package Version 1.15-4.

\section{Preintervention Comparability}

The assignment of children to groups was randomized, and as expected, none of the characteristics were significantly different between groups at baseline: age $(\mathrm{EG}=45.5, \mathrm{CG}=$ $48.5, p=.585$ ), gender ( $\mathrm{EG}=87 \%$ of males, $\mathrm{CG}=93 \%$ of males, $p=.543$ ), mother's level of education ( $\mathrm{EG}=20 \%$ degree, $\mathrm{CG}=13 \%$ degree, $p=.625$ ), ADOS severity (EG $=16.1, \mathrm{CG}=15.1, p=.557)$, ADOS communication $(\mathrm{EG}=$ $5.1, \mathrm{CG}=3.8, p=.196)$, ADOS social interaction $(\mathrm{EG}=10.5, \mathrm{CG}=11.1, p=.62), \mathrm{GMDS}-\mathrm{GQ}(\mathrm{EG}=59.4$, $\mathrm{CG}=60.7, p=.865)$, VABS communication $(\mathrm{EG}=2.2, \mathrm{CG}$ $=1.6, p=.316)$, VABS Daily Living Skills $(\mathrm{EG}=2, \mathrm{CG}=2, p$ $=.983)$, VABS socialization $(\mathrm{EG}=1.7, \mathrm{CG}=1.7, p=.66)$, VABS motor skills $(\mathrm{EG}=2.2, \mathrm{CG}=2, p=.714)$, and finally attention program $(\mathrm{EG}=2.2, \mathrm{CG}=2.1, p=.873)$, receptive identification of objects program $(\mathrm{EG}=41.9, \mathrm{CG}=42.3, p=$ $.981)$, and imitation of actions with objects program $(\mathrm{EG}=53.1$, $\mathrm{CG}=41.9, p=.335$ ) regarding behavioral standard therapy.

\section{Postintervention Comparability}

Regarding the amount of mastered targets of the standard therapy, we report the comparison between groups at posttraining assessment following three educational programs, attention (EG: $M=2.9, S D=2.6$; CG: $M=2.0, S D=1.9 ; p=$ .348), receptive identification of objects (EG: $M=60.7, S D$ $=55.5 ; \mathrm{CG}: M=52.9, S D=59.7 ; p=.712)$, and imitation of 
Table 2. Logistic Regression With Target Improvement as Dependent Variable.

\begin{tabular}{|c|c|c|c|c|c|c|c|c|c|c|c|c|}
\hline Target & \multicolumn{4}{|c|}{ Attention } & \multicolumn{4}{|c|}{ Imitation of Actions With Objects } & \multicolumn{4}{|c|}{ Receptive Identification of Objects } \\
\hline Baseline target level & 0.016 & .185 & 0.086 & .931 & -.016 & .014 & -1.135 & .256 & -0.007 & .008 & -0.893 & .372 \\
\hline
\end{tabular}

Table 3. Linear Regression With Average Game Score as Dependent Variable.

\begin{tabular}{|c|c|c|c|c|c|c|c|c|c|c|c|c|}
\hline \multirow{2}{*}{ Target } & \multicolumn{4}{|c|}{ Attention $\left(R^{2}=.146\right)$} & \multicolumn{4}{|c|}{$\begin{array}{c}\text { Imitation of Actions } \\
\text { With Objects }\left(R^{2}=.480\right)\end{array}$} & \multicolumn{4}{|c|}{$\begin{array}{l}\text { Receptive Identification } \\
\text { of Objects }\left(R^{2}=.298\right)\end{array}$} \\
\hline & $\beta$ & $S E$ & $t$ Value & $p$ Value & $\beta$ & SE & $t$ Value & $p$ Value & $\beta$ & $S E$ & $t$ Value & $p$ Value \\
\hline Baseline target level & 4.87 & 6.58 & .74 & .47 & 0.13 & 0.05 & 2.74 & $.02 *$ & 0.21 & 0.20 & 1.05 & .32 \\
\hline Age & 0.11 & 1.19 & .09 & .93 & -0.01 & 0.10 & -0.13 & .90 & 0.68 & 0.66 & 1.04 & .32 \\
\hline Gender & -46.61 & 48.6 & -.96 & .36 & -1.24 & 3.77 & -0.33 & .75 & 14.77 & 31.0 & 0.48 & .65 \\
\hline
\end{tabular}

$*_{\alpha}<.05$.

actions with objects (EG: $M=64.3, S D=40.7$; CG: $M=54.2$, $S D=29.5 ; p=.441)$. Therefore, even if after 4 weeks children in the EG showed better learning than the children in the $\mathrm{CG}$ within standard therapy, the differences between groups did not overstep the significance level. However, applying the logistic regression analysis, the statistics showed the effect of training exclusively for the first of the three programs (attention, $\beta=$ $1.736, p=.059$; receptive identification of objects, $\beta=1.193$, $p=.209$; and imitation of actions with objects, $\beta=0.177, p=$ .837); for detailed information, see Table 2. Also, concerning the second hypothesis of the study, the linear regression analysis confirmed the influence of the children's abilities at baseline (mastered targets of the standard therapy) on game scores (means), but this effect was achieved only for the imitation app $(\beta=0.13, p=.02)$ and not for the attention app $(\beta=4.87, p=$ $.47)$ and vocabulary app $(\beta=0.21, p=.32$; see Table 3$)$. This phenomenon can be explained by a fine virtual reproduction of the imitative exercises demanded of children within the behavioral standard therapy. Finally, we report the differences between game scores at baseline (average of the first three sessions) and the best scores reached for the attention app (baseline $=56.49$, average of the best scores $=168.27$ ), vocabulary app (baseline $=48.97$, mean of the best scores $=$ 113.69), and imitation app (baseline $=23.40$, mean of the best scores $=20.36$ ) showing a considerable increment of scores with tablet applications, particularly for attention and vocabulary apps, while children had already reached the best scores for the imitation app after only a few sessions, demonstrating the intrinsic simplicity of the game. In fact, the best sessions were represented by the eighth for attention, the seventh for vocabulary, and the fourth for the imitation app. Neither the number of online accesses nor the amount of time spent on games were significantly different across participants. Similarly, the time spent on the three applications had no significant correlation with the averages and best game scores, showing that the intensity of the exercise had no effect.

\section{Discussion}

This study sheds light on different questions concerning the link between technology and learning, above all for special education. Research studies on the effectiveness of traditional technology and handheld electronic devices on the skills of children with diverse neuropsychiatric disorders have increased over the last decades, showing advantages in their use (Grynszpan et al., 2014; Odom et al., 2015; Stephenson \& Limbrick, 2015; Wass \& Porayska-Pomsta, 2014). Specifically, different researchers have tested the development and the implementation of electronic tools to enhance specific cognitive skills for children with ASD, such as vocabulary and attention (Jeffries et al., 2016; Moore \& Calvert, 2000; Whalen et al., 2010). Similarly, the first goal of our research team was to assess the efficacy of additional tablet application training (attention, vocabulary, and imitation) for children with ASD, in contrast with an internal CG which followed only the behavioral standard therapy. The training lasted 4 weeks, and at postintervention assessment, the EG showed greater progress within standard therapy than the internal CG for all three educational programs investigated: attention, imitation of actions with objects, and receptive identification of objects. Unfortunately, these differences did not exceed the significance level. However, the probability of making progress in mastered targets at postintervention assessment was higher for the EG than the $\mathrm{CG}$, especially for the attention program, as shown by logistic regression analysis. These results have reinforced our belief that we have created a potentially effective tool which reproduces similar exercises offered in the behavioral therapy. In fact, the group of children using the tablet applications could represent an advantage in the learning of adaptive abilities, such as visual attention and comprehension of common object and actions. Accordingly, tablet applications can also offer a new learning environment in the classroom, where the presence of a trained teacher is often required for the implementation of 
behavioral interventions. In these cases, technology that integrates effective teaching methodologies with evidence-based game mechanics can represent either a momentary alternative to standard teaching or a complementary educational instrument to increase children's skills through an individualized educational program.

Furthermore, looking at the descriptive and inferential data on games, it seems that the tablet applications were suited to our participants, since the number of correct responses increased during the training. After only a few sessions the children doubled their initial scores, showing great motivation during the games. However, the applications also proved too easy for the majority of children, because the best scores were acquired before the end of the intervention, and as a result, the outcomes could be influenced by a possible loss of motivation for the games. The data that can confirm this explanation are also supported by the absence of correlation between time spent on the game and the outcomes. In spite of this trend, the project staff are already working to modify and extend the games, in order to enhance their appeal, efficacy, and complexity by the introduction of new game levels and fun animated activities, addressing the third study question.

Nevertheless, a notable result of this research is the impact that the children's skills at baseline had on the same exercises transferred into the games, above all for the imitation program by linear regression analysis. This effect can be explained by the capacity of the imitation app to capture the actual ability practiced by preschoolers within ordinary educational trials, responding to our second hypothesis, while the other two applications, attention and vocabulary, could have oversimplified the format of the responses demanded of children, decreasing the correlation between real and virtual ability. In fact, concerning the standard therapy, the attention program comprised more complex behaviors such as eye contact and joint attention than the related application; similarly, the vocabulary app could seem to have a poorer learning environment (only 2-D materials, absence of visual model, too highly structured teaching, etc.) than face-to-face therapy.

Another strong point of the project is the reliability of data recording, as the scores were gathered on an online database, with a lower margin for error than with manual procedures. At the same time, we monitored other possible threats to the internal validity of the study, without altering the quantity of direct supervision of the standard therapy and maintenance therapies provided by parents at home. No other cognitive or behavioral interventions were followed by the children other than our services. Moreover, the advantage of having created applications that reproduced similar exercises to the behavioral therapy leads to an easier generalization of trained skills, especially if the children continue to follow standard teaching methods. Games may be more effective when they are paired with other activities that supplement the game-based instruction and encourage generalization of the material beyond the game (Ploog, Scharf, Nelson, \& Brooks, 2013). In other cases, generalization problems can be explained by the simplified nature of the technological environment (Wass \& Porayska-Pomsta, 2014). For this purpose, Whyte, Smyth, and Scherf (2015) defined training effects as the generalization of skills which occur within the training, near transfer as those effects that lead to measurable improvements in similar training, and far transfer with regard to daily living situations, suggesting strategies to tackle these problems through games (story line, gradual game advances, from short-term to long-term goals, rewards and feedback, personalized learning with tutoring, and progress monitoring). In the same way, the current training shows an influence only on the training effect and near transfer, because we did not evaluate the same behavior at school or at the children's homes, but only in the treatment center, not controlling a possible generalization within naturalistic environments. Furthermore, we did not investigate probable indirect effects of training on other abilities of the children, such as visual motor and actual play skills, although this analysis will be possible when we have modified the complexity of the games. It is still not clear if training could be more effective at the beginning of ABA treatment than after 1 year, as our research design proposed; it is possible that after 1 year of intensive treatment some specific abilities may not be easily increased.

Finally, although this work represents an innovative praxis for special education methods, we suggest interpreting our data with caution, particularly because the sample may not be representative of the entire population with ASD. Specifically, all the children followed ABA treatment, and so they had familiarity with behavioral targets, having base skills with regard to imitation of objects and comprehension of simple instructions, as the baseline assessment had shown, and as a result, these base competencies could have been prerequisites for successful usage of the tablet applications. On the other hand, the simple nature of these games means that children using them would not necessarily need to have existing skills. In accordance with the last supposition, the tablet applications could be suited to low-functioning children, as our sample study shows, providing simple games with little cognitive and motor burden. Eventually, future research could explore whether or not these games are also suitable for children with ASD or ID not previously included in behavioral or cognitive interventions in order to support learning before and at the beginning of standard individualized educational plans.

\section{Conclusion}

Considering the diversity of phenotypes in ASDs, clinicians and technicians will be increasingly requested to form partnerships with the academic and industrial world to assemble experience and competencies in order to create efficient products for children and adults with special needs. In addition, professionals will be required to acquire funds from private and public financial institutes to support research and interventions (McCleery, 2015). To date, modern technology has been shown to be a useful learning tool because essentially it offers students fun animated presentations, use of large screens, repetition of specific learning tasks, application of techniques, demonstrated efficacy such as video modeling, visual prompting, audio coaching, performance feedback, reinforcement, and self-management. 
The current study shows the capability of tablet applications to reproduce effective educational training for children with ASDs through the presentation of repetitive trials, presented with behavioral teaching strategies. At the same time, the children in our study increased their game scores in just a few sessions, displaying a spontaneous, immediate approach to virtual games. Future goals will comprise improving our technological products, evaluating their utility with related benefits for children with developmental disorders. To conclude, we suggest that the selection of a specific electronic device for children with special needs should be essentially personalized by clinical staff in order to achieve the perfect combination between virtual learning and standard teaching methods.

\section{Acknowledgments}

The authors would like to thank the families following treatment programs at the Autism Centre "Una Breccia nel Muro" project and the professional staff, Selena Ciardi, Maria Teresa Dipierro, Bruna Monopoli, Gaia Ciardo, Vanessa Mancini, Graziana Ruel, Paolo Pellegrino, Daniele Caldarelli, Sergio de Julio, and Wink Group, for their hard work. Lastly, we would like to thank Prof. Alberto Zuliani for his precious suggestions during the project's development.

\section{Declaration of Conflicting Interests}

The author(s) declared no potential conflicts of interest with respect to the research, authorship, and/or publication of this article.

\section{Funding}

The author(s) disclosed receipt of the following financial support for the research, authorship, and/or publication of this article: The project was conducted in collaboration with the Association "Una Breccia nel Muro" and the pediatric hospital Bambino Gesù under the sponsorship of the TIM (Telecom Italia Group) Foundation. The sponsor and contributor did not have any role in the collection, analysis, and interpretation of data; in writing the report; or in the decision to submit the article for publication.

\section{References}

Achmadi, D., Kagohara, D. M., van der Meer, L., O'Reilly, M. F., Lancioni, G. E., Sutherland, D., ... Sigafoos, J. (2012). Teaching advanced operation of an iPod-based speech generating device to two students with autism spectrum disorders. Research in Autism Spectrum Disorders, 6, 1258-1264. doi:10.1016/j.rasd. 2012.05.005

American Psychiatric Association. (2013). Diagnostic and statistical manual of mental disorders, 5th ed. Washington, DC: American Psychiatric Publishing.

Burke, R. V., Andersen, M. N., Bowen, S. L., Howard, M. R., \& Allen, K. D. (2010). Evaluation of two instruction methods to increase employment options for young adults with autism spectrum disorders. Research in Developmental Disabilities, 31, 1223-1233. doi:10.1016/j.ridd.2010.07.023

Cihak, D., Fahrenkrog, C., Ayres, K., \& Smith, C. (2010). The use of video modeling via a video iPod and a system of least prompts to improve transitional behaviors for students with autism spectrum disorders in the general education classroom. Journal of
Positive Behavior Interventions, 12, 103-115. doi:10.1177/ 1098300709332346

Delano, M. E. (2007). Video modeling interventions for individuals with autism. Remedial and Special Education, 28, 33-42. doi:10. 1177/07419325070280010401

Fava, L., \& Strauss, K. (2011). Cross-setting complementary staff-and parent-mediated early intensive behavioral intervention for young children with autism: A research-based comprehensive approach. Research in Autism Spectrum Disorders, 5, 512-522. doi:10.1016/ j.rasd.2010.06.017

Flores, M., Musgrove, K., Renner, S., Hinton, V., Strozier, S., Franklin, S., \& Hil, D. (2012). A comparison of communication using the Apple iPad and a picture-based system. Augmentative and Alternative Communication, 28, 74-84.doi:10.3109/07434618.2011.644579

Gal, E., Bauminger, N., Goren-Bar, D., Pianesi, F., Stock, O., Zancanaro, M., \& Weiss, P. L. (2009). Enhancing social communication of children with high functioning autism through a co-located interface. AI and Society, the Journal of Human-Centred Systems, 24, 1. doi:10.1007/s00146-009-0199-0

Gentry, T., Lau, S., Molinelli, A., Fallen, A., \& Kriner, R. (2012). The Apple iPod Touch as a vocational support aid for adults with autism: Three case studies. Journal of Vocational Rehabilitation, 37, 75-85. doi:10.3233/JVR-2012-0601

Griffiths, R. (2006). Griffiths Mental Development Scales extended revised manual. Firenze, Italy: Giunti Organizzazioni Speciali.

Grynszpan, O., Weiss, P. L. T., Perez-Diaz, F., \& Gal, E. (2014). Innovative technology-based interventions for autism spectrum disorders: A meta-analysis. Autism, 18, 346-361. doi:10.1177/ 1362361313476767

Hourcade, J. P., Bullock-Rest, N. E., \& Hansen, T. E. (2012). Multitouch tablet applications and activities to enhance the social skills of children with autism spectrum disorders. Personal and Ubiquitous Computing, 16, 157-168. doi:10.1007/s00779-011-0383-3

Ivens, J., \& Martin, N. (2002). A common metric for the Griffiths Scales. Archives of Disease in Childhood, 87, 109-110. Retrieved from http://adc.bmj.com/content/87/2/109.short

Jeffries, T., Crosland, K., \& Miltenberger, R. (2016). Evaluating a tablet application and differential reinforcement to increase eye contact in children with autism. Journal of Applied Behavior Analysis, 49, 182-187. doi:10.1002/jaba.262

Jowett, E. L., Moore, D. W., \& Anderson, A. (2012). Using an iPadbased video modelling package to teach numeracy skills to a child with an autism spectrum disorder. Developmental Neurorehabilitation, 15, 304-312. doi:10.3109/17518423.2012.682168

Kagohara, D. M., Sigafoos, J., Achmadi, D., O’Reilly, M., \& Lancioni, G. (2012). Teaching children with autism spectrum disorders to check the spelling of words. Research in Autism Spectrum Disorders, 6, 304-310. doi:10.1016/j.rasd.2011.05.012

Kagohara, D. M., van der Meer, L., Achmadi, D., Green, V. A., O’Reilly, M., Mulloy, A.,,... Sigafoos, J. (2010). Behavioral intervention promotes successful use of an iPod-based communication device by an adolescent with autism. Clinical Case Studies, 9, 328-338. doi:10.1177/1534650110379633

Kagohara, D. M., van der Meer, L., Ramdoss, S., O'Reilly, M. F., Lancioni, G. E., Davis, T. N., ... Sigafoos, J. (2013). Using iPods $\mathbb{R}$ and iPads $\mathbb{R}$ in teaching programs for individuals with 
developmental disabilities: A systematic review. Research in Developmental Disabilities, 34, 147-156. doi:10.1016/j.ridd.2012.07.027

Kinney, E. M., Vedora, J., \& Stromer, R. (2003). Computer-presented video models to teach generative spelling to a child with an autism spectrum disorder. Journal of Positive Behavior Interventions, 5, 22-29. doi:10.1177/10983007030050010301

Lerman, D. C., Dittlinger, L. H., Fentress, G., \& Lanagan, T. (2011). A comparison of methods for collecting data on performance during discrete trial teaching. Behavior Analysis in Practice, 4, 53-62. Retrieved from http://www.ncbi.nlm.nih.gov/pmc/articles

Lofland, K. B. (2016). The use of technology in the treatment of autism. In T. A. Cardon (Ed.), Technology and the treatment of children with autism spectrum disorder (pp. 27-35). Switzerland: Springer International Publishing. doi: 10.1007/978-3-319-208725_2

Lord, C., Risi, S., Lambrecht, L., Cook, E. H., \& Leventhal, B. L. (2000). The autism diagnostic observation schedule-generic. A standard measure of social and communication deficits associated with the spectrum of autism. Journal of Autism and Developmental Disorders, 30, 205-223. doi:10.1023/A:1005592401947

Lord, C., Rutter, M., \& Le Couteur, A. (1994). Autism diagnostic interview-revised. A revised version of a diagnostic interview for caregivers of individuals with possible pervasive developmental disorders. Journal of Autism and Developmental Disorders, 24, 659-685. doi:10.1007/BF02172145

Marchiori, E. J., Torrente, J., del Blanco, Á., Moreno-Ger, P., Sancho, P., \& Fernández-Manjón, B. (2012). A narrative metaphor to facilitate educational game authoring. Computers \& Education, 58, 590-599. doi:10.1016/j.compedu.2011.09.017

McCleery, J. P. (2015). Comment on technology-based intervention research for individuals on the autism spectrum. Journal of Autism and Developmental Disorders, 45, 3832-3835. doi:10.1007/ s10803-015-2627-y

Moore, M., \& Calvert, S. (2000). Brief report: Vocabulary acquisition for children with autism: Teacher or computer instruction. Journal of Autism and Developmental Disorders, 30, 359-362. doi:10. 1023/A:1005535602064

Odom, S. L., Thompson, J. L., Hedges, S., Boyd, B. A., Dykstra, J. R., Duda, M. A., ... Bord, A. (2015). Technology-aided interventions and instruction for adolescents with autism spectrum disorder. Journal of Autism and Developmental Disorders, 45, 3805-3819. doi:10.1007/s10803-014-2320-6

Partington, J., \& Sundberg, M. (1998). The Assessment of Basic Language and Learning Skills (The ABLLS): An assessment, curriculum guide, and skills tracking system for children with autism or other developmental disabilities. Pleasant Hill, CA: Behavior Analysts.

Piper, A. M., O’Brien, E., Morris, M. R., \& Winograd, T. (2006). SIDES: A cooperative tabletop computer game for social skills development. CSCW '06, Proceedings of the 2006 20th Anniversary Conference on Computer Supported Cooperative Work, 1-410. November 4-8, 2006, Canada: Banff, Alberta. doi: 10. $1145 / 1180875.1180877$

Ploog, B. O., Scharf, A., Nelson, D., \& Brooks, P. J. (2013). Use of computer-assisted technologies (CAT) to enhance social, communicative, and language development in children with autism spectrum disorders. Journal of Autism and Developmental Disorders, 43, 301-322. doi:10.1007/s10803-012-1571-3

Ryan, R. M., Rigby, C. S., \& Przybylski, A. (2006). The motivational pull of video games: A self-determination theory approach. Motivation and Emotion, 30, 344-360. doi:10.1007/s11031-006-9051-8 Smith, T., Scahill, L., Dawson, G., Guthrie, D., Lord, C., Odom, S., .. . Wagner, A. (2007). Designing research studies on psychosocial interventions in autism. Journal of Autism and Developmental Disorders, 37, 354-366. doi:10.1007/s10803-006-0173-3

Sparrow, S. S., Balla, D. A., \& Cicchetti, D. V. (1984). Vineland adaptive behavior scales. Circle Pines, MN: American Guidelines Services.

Stephenson, J., \& Limbrick, L. (2015). A review of the use of touchscreen mobile devices by people with developmental disabilities. Journal of Autism and Developmental Disorders, 45, 3777-3791. doi:10.1007/s10803-013-1878-8

Sundberg, M. L., \& Partington, J. W. (1999). The need for both discrete train and natural environment language teaching for children with autism. In P. M. Ghezzi, W. L. Williams, \& J. E. Carr (Eds.), Autism: Behavior analytic perspectives (pp. 139-156). Reno, NV: Context Press.

van der Meer, L., Didden, R., Sutherland, D., O’Reilly, M. F., Lancioni, G. E., \& Sigafoos, J. (2012). Comparing three augmentative and alternative communication modes for children with developmental disabilities. Journal of Developmental and Physical Disabilities, 24, 451-468. doi:10.1007/s10882-012-9283-3

van der Meer, L., Kagohara, D. M., Achmadi, D., Green, V. A., O'Reilly, M. F., Herrington, C., \& Sigafoos, J. (2011). Teaching functional use of an iPod-based speech-generating device to individuals with developmental disabilities. Journal of Special Education Technology, 26, 1-11. doi:10.1177/01626434110 2600301

van der Meer, L., Kagohara, D. M., Achmadi, D., O'Reilly, M. F., Lancioni, G. E., Sutherland, D., \& Sigafoos, J. (2012). Speechgenerating devices versus manual signing for children with developmental disabilities. Research in Developmental Disabilities, 33, 1658-1669. doi:10.1016/j.ridd.2012.04.004

van der Meer, L., Sutherland, D., O’Reilly, M. F., Lancioni, G. E., \& Sigafoos, J. (2012). A further comparison of manual signing, picture exchange, and speech generating devices as communication modes for children with autism spectrum disorders. Research in Autism Spectrum Disorders, 6, 1247-1257. doi:10.1016/j.rasd. 2012.04.005

Warren, Z., McPheeters, M. L., Sathe, N., Foss-Feig, J. H., Glasser, A., \& Veenstra-VanderWeele, J. (2011). A systematic review of early intensive intervention for autism spectrum disorders. Pediatrics, 127, e1303-e1311. doi:10.1542/peds.2011-0426

Wass, S. V., \& Porayska-Pomsta, K. (2014). The uses of cognitive training technologies in the treatment of autism spectrum disorders. Autism, 18, 851-871. doi:10.1177/1362361313499827

Whalen, C., Moss, D., Ilan, A. B., Vaupel, M., Fielding, P., Macdonald, K., ... Symon, J. (2010). Efficacy of teach town: Basics computer-assisted intervention for the intensive comprehensive autism program in Los Angeles unified school district. Autism, 14, 179-197. doi:10.1177/1362361310363282

Whyte, E. M., Smyth, J. M., \& Scherf, K. S. (2015). Designing serious game interventions for individuals with autism. Journal of Autism 
and Developmental Disorders, 45, 3820-3831. doi:10.1007/ s10803-014-2333-1

\section{Author Biographies}

Marco Esposito is psychologist, researcher and supervisor at the Autism Research and Treatment Centre "una breccia nel muro" (UBM).

Janette Sloan, B.Sc (Hons), RSA Dip TEFLA, speaking examiner for Cambridge ESOL, professor at the Cambridge School Salerno.

Andrea Tancredi is associate professor of Statistics, Department of Methods and Models for Economy Territory and Finance, Sapienza University of Rome.

Giovanna Gerardi is psychotherapist and supervisor at the Centre UBM.
Paola Postiglione is psychologist and research assistant at the Centre UBM.

Francesca Fotia, MSc Psychology, PhD student at the University of Essex.

Eleonora Napoli is a fellow psychologist of the Child Neuropsychiatry Unit of the Pediatric Hospital Bambino Gesù, Department of Neuroscience, Rome.

Luigi Mazzone is research assistant Professor at the Division of Child Psychiatry at the Tor Vergata University, Rome, Italy.

Giovanni Valeri is a child neuropsychiatrist of the Child Neuropsychiatry Unit of the Pediatric Hospital Bambino Gesù, Department of Neuroscience, Rome.

Stefano Vicari is the head of the Child Neuropsychiatry Unit of the Pediatric Hospital Bambino Gesù, Department of Neuroscience, and Professor of Neuropsychiatry, University LUMSA, Rome. 